\title{
Evaluative meaning and temporal coding
}

\author{
MARGARET W. MATLIN \\ State University of New York, Geneseo, New York 14454 \\ CHRISTINE K. BEARD \\ State University of New York, Buffalo, New York 14214 \\ and \\ PAUL ROSE \\ State University of New York, Geneseo, New York 14454
}

\begin{abstract}
Previous research has demonstrated that evaluative meaning is related to recall accuracy; pleasant items are recalled more accurately than less pleasant items. The present experiment was conducted to determine whether evaluative meaning was also related to temporal coding accuracy. Subjects saw three separate homogeneous lists, one pleasant, one neutral, and one unpleasant. The results demonstrated that: (1) pleasant words were recalled more accurately than neutral or unpleasant words, (2) evaluative meaning had no influence on the accuracy of temporal position judgments, and (3) evaluative meaning had no influence on subjects' confidence in their temporal position judgments.
\end{abstract}

The Pollyanna principle states that pleasant information is processed more efficiently and more accurately than less pleasant information (Matlin \& Stang, 1978). This selectivity phenomenon has been demonstrated in language, decision making, and perception, but it has been particularly well documented in memory. A review of approximately 100 studies concluded that people learn and recall pleasant items more accurately than less pleasant items.

To date, however, no research has been reported on the relationship between pleasantness and temporal coding. Are people more accurate in identifying when they have seen pleasant items, in contrast to less pleasant items? Previous research has addressed various task attributes that might influence temporal coding (e.g., Toglia \& Kimble, 1976; Underwood, 1977; Underwood \& Malmi, 1978). However, we have been unable to locate any research concerning the relationship between semantic aspects of the stimuli and temporal coding.

A pilot study conducted on mixed lists of pleasant, neutral, and unpleasant words demonstrated that evaluative meaning did not have a significant influence on measures of temporal coding. However, these results were difficult to interpret because of severe floor effects and because of the heterogeneity of the lists. Therefore, the present study employed familiar words, shorter lists, and homogeneous lists.

In this experiment, subjects saw three separate lists of 12 items: one pleasant list, one neutral list, and one unpleasant list. We hypothesized that: (1) pleasant words would be recalled more accurately, (2) the

The authors would like to thank Barry J. Stapsky and Anthony D. DelBove for their help and advice with the statistical analy sis. temporal position of pleasant words should be judged more accurately, and (3) confidence judgments regarding temporal position accuracy would be higher for pleasant words. Although we could find no previous comparisons of confidence estimates for items varying in evaluative meaning, we found other evidence suggesting this relationship. For example, several studies have demonstrated that subjects classify pleasant words faster than less pleasant words (e.g., Geller, Whitman, \& Beamon, 1971; Lehr, Bergum, \& Standing, 1966; Osgood, Suci, \& Tannenbaum, 1957).

\section{METHOD}

\section{Subjects}

Ninety-five male and female undergraduates attending the State University of New York at Geneseo served as subjects in this study. They participated in the experiment in order to fulfill a requirement for an introductory psychology course. Subjects were tested in 12 groups of 5-10 subjects each. Each group represented 1 of the 12 list by order combinations.

\section{Stimuli}

Using Toglia and Battig's (1978) Handbook of Semantic Word Norms, four lists of 12 items each were constructed for each of the three evaluative categories: pleasant (Toglia-Battig ratings of 5.50-7.00), neutral (3.25-4.75), and unpleasant $(1.00-2.50)$. All words were of moderately high familiarity (Toglia-Battig ratings of 5.70-6.50). All lists were equated for concreteness, parts of speech, and number of syllables. Three list orders were prepared using a Latin square counterbalancing design: PNU, UPN, and NUP. Each of the three list orders was applied to each of the four word lists, creating 12 lists by order combinations.

A Carousel slide projector presented each word for $5 \mathrm{sec}$. The three lists were presented sequentially, with a 1-min break between lists. After a 1-min delay, subjects were requested to recall words from all three lists in any order they wished. Then they received three-page booklets with a different list printed on each page. They were instructed to place the numbers 1-12 
Table 1

\begin{tabular}{lcccc}
\hline & & \multicolumn{3}{c}{ Word Category } \\
\cline { 2 - 4 } & Pleasant & Neutral & Unpleasant \\
\hline 1. Number of words recalled & 5.2 & 3.1 & 4.2 \\
2. Mean deviation of subjects' judgments from true temporal position & 2.7 & 2.8 & 2.5 & 3.9 \\
3. Mean confidence in accuracy of judged temporal position & 3.8 & 3.6 & 3.9 \\
\hline
\end{tabular}

next to each word to indicate the word's position on the original list. Finally, they were asked to assess their confidence in each word position judgment, using a 1 (not at all confident) to 7 (extremely confident) scale.

\section{RESULTS}

An analysis of variance conducted on the number of items correctly recalled showed that pleasantness had a highly significant effect $[\mathrm{F}(2,6)=51.09, \mathrm{MSe}=2.11$, $\mathrm{p}<.05]^{1}$ As Table 1 shows, pleasant words were recalled most accurately, and neutral words were recalled least accurately. The interaction of pleasantness and list order was also significant $[F(4,12)=3.76$, $\mathrm{MSe}=3.24, \mathrm{p}<.05]$. Inspection of the means showed that recall for each kind of word was substantially lower when that list was presented second (i.e., as the middle list), rather than first or third.

Temporal position accuracy was measured in terms of the absolute value of the deviation between the judged temporal position and the true temporal position. Pleasantness had no influence on accuracy of temporal coding $[\mathrm{F}(2,6)=1.81, \mathrm{MSe}=2.24, \mathrm{p}<.05]$. The interaction of pleasantness and list order was significant $[\mathrm{F}(4,12)=6.37, \quad \mathrm{MSe}=1.25, \mathrm{p}<.05]$. Inspection showed that temporal position accuracy was greatest for the category of word that was presented on the first list. Thus, accuracy was greatest for pleasant words with the PNU order, for the unpleasant words with the UPN order, and for the neutral words with the NUP order.

Subjects' confidence in their temporal position judgments was not influenced by pleasantness $[F(2.6)=$ 2.36, $\mathrm{MSe}=1.04, \mathrm{p}<.05]$. No main effects or interactions were significant in this analysis.

\section{DISCUSSION}

The experiment demonstrated selective recall. Consistent with the previous literature (Matlin \& Stang, 1978), subjects recalled pleasant words most accurately and neutral words least accurately. However, subjects did not show greater temporal coding accuracy for pleasant words. Even with a list of words that produced selective recall, there was no evidence of selective temporal coding. Furthermore, subjects were no more confident in their temporal judgments when the stimuli were pleasant than when they were less pleasant.

The coding processes involved in recording the time at which an item was experienced must be substantially different from the coding of the item itself. Thus we can recall pleasant items with greater accuracy than other items, but we are no more likely to remember when these pleasant items occurred.

\section{REFERENCES}

Geller, E. S., Whitman, C. P., \& Beamon, W. S. Effects of expressed and measured value preference on decision speed. Psychonomic Science, 1971, 24, 84-86.

KePPEL, G. Design and analysis: $A$ researcher's handbook. Englewood Cliffs, N.J: Prentice-Hall, 1973.

Lehr, D. J., Bergum, B. O., \& Standing, T. E. Response latency as a function of stimulus affect and presentation order. Perceptual and Motor Skills, 1966, 23, 1111-1116.

Matlin, M. W., \& Stang, D. J. The Pollyanna principle: Selectivity in language, memory, and thought. Cambridge, Mass: Schenkman, 1978.

Osgood, C. E., Suci, G. T., \& Tannenbaum, P. H. The measurement of meaning. Urbana: University of Illinois Press, 1957.

Toglia, M. P., \& Battig, W. F. Handbook of semantic word norms. Hillsdale, N.J: Erlbaum, 1978.

Toglia, M. P., \& Kimble, G. A. Recall and use of serial position information. Journal of Experimental Psychology: Human Learning and Memory, 1976, 2, 431-445.

UNDERWOOD, B. J. Temporal codes for memories: Issues and problems. Hillsdale, N.J: Erlbaum, 1977.

Underwood, B. J., \& Malmi, R. A. An evaluation of measures used in studying temporal codes for words within a list. Journal of Verbal Learning and Verbal Behavior, 1978, 17, 279-293.

\section{NOTE}

1. In this analysis and in all subsequent analyses, the interaction of pleasantness and list was used as the error term, to test the significance of the main effect of pleasantness, following Keppel's (1973) recommendation that the error term should contain the effect (e.g., pleasantness) plus one random independent variable (e.g., list). To test the significance of the interaction of pleasantness and order, the error term used was pleasantness $X$ order $X$ list.

(Received for publication March 27, 1981.) 